\title{
A INCLUSĀO DA CRIANÇA DE 6 ANOS NO ENSINO FUNDAMENTAL NA REDE MUNICIPAL DE VÁRZEA PAULISTA: CRIANDO A POSSIBILIDADE DO NOVO
}

\author{
Alvina do Carmo da S. Souza \\ Celisa Carrara Bonamigo \\ Cristiane Machado \\ Leonice de Brito
}

\section{RESUMO}

O objetivo desse texto é descrever o processo de implantação do ensino fundamental de 9 anos na rede municipal de Várzea Paulista - SP e tecer algumas considerações analíticas sobre essa política educacional. Relata a criação do grupo de trabalho que sistematizou a proposta pedagógica para o trabalho com as crianças de 6 anos no ensino fundamental e os conceitos de sistema e identidade que fundamentaram as discussões sobre a construção do currículo na rede municipal. Como análise da proposta ressaltamos algumas conseqüências empíricas e operacionais do processo de implantação e também as resistências que perpassaram os debates e as ações propostas.

\section{PALAVRAS-CHAVE}

Ensino fundamental de 9 anos; Currículo; Avaliação; Proposta pedagógica

\section{THE INCLUSION OF 6 YEARS OLD CHILDREN IN THE FUNDAMENTAL EDUCATION IN THE MUNICIPAL NETWORK OF VÁRZEA PAULISTA: CREATING THE POSSIBILITY OF THE NEW}

\begin{abstract}
This text aims at describing the implementation process of the nine-year fundamental education in the municipal network of Várzea Paulista - SP as well weaving some analytical considerations on this educational policy. It describes the creation of the work group which systematized the pedagogic proposal to work with six-year-old children in fundamental education and the concepts of system and identity that grounded the discussions on curriculum elaboration in the municipal network. As a proposal for analysis, we highlight a few empirical and operational consequences in the implementation process in addition to the resistance faced throughout the debates and proposed actions.
\end{abstract}

\section{KEYWORDS}

Nine-year fundamental education; Curriculum; Evaluation; Pedagogic proposal 
Este texto tem o objetivo de relatar e tecer análises sobre a implantação do ensino fundamental de 9 anos no sistema municipal de educação de Várzea Paulista - S.P. e a conseqüente inclusão da criança de 6 anos no ensino fundamental. Para tanto, inicialmente, descreveremos os desdobramentos do processo de implantação do ensino fundamental de 9 anos e, posteriormente, analisaremos as principais conseqüências e resistências dessa política, a partir da ótica da gestão do sistema.

\section{INICIANDO O CAMINHO}

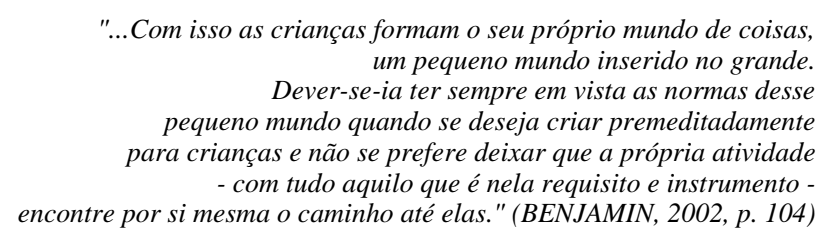

A discussão sobre a possibilidade de implantação, em 2008, do ensino fundamental de 9 anos na rede municipal em Várzea Paulista teve início no começo do segundo semestre de 2007 quando a equipe pedagógica ${ }^{1}$ da secretaria se reuniu para organizar o atendimento das crianças ingressantes no ensino fundamental no ano seguinte. Os dados levantados foram analisados pelo grupo gestor ${ }^{2}$ da secretaria de educação que decidiu expor a proposta de implantação do ensino fundamental de 9 anos ao Prefeito Eduardo Tadeu Pereira e sugerir sua execução a partir de 2008. Em 29 de agosto, após reunião com o Prefeito, ficou decidido que a equipe pedagógica faria os encaminhamentos necessários para a implantação do ensino fundamental de 9 anos já em $2008^{3}$.

As ações da equipe pedagógica para desencadear a implantação do ensino fundamental de 9 anos foram organizadas em duas dimensões. A primeira delas, no âmbito da organização da própria rede física, teve o objetivo de distribuir as crianças nos períodos e salas disponíveis nas escolas e foi feita pela equipe em conjunto com as gestoras das unidades

\footnotetext{
1 - À época a equipe pedagógica era composta pelas Supervisoras de Ensino Celiana Luzia de Almeida Santos e Celisa Carrara Bonamigo, Diretora Pedagógica Leonice de Brito, Diretora de Creches Alvina do C. da S. Souza e Supervisora Departamental Cristiane Machado.

2 - Composto pela equipe pedagógica acrescida dos Assessores Técnicos Maria José Azevedo e Ronaldo Pereira, Diretor Administrativo Emerson Righi, Diretora de Projetos Especiais Marilza Barnabé e o Secretário Luiz Antonio Raniero.

3 - É importante ressaltar que a implantação do ensino fundamental de 9 anos se tornou obrigatória com a aprovação da lei federal 11.274 de 06.02.2006. Os sistemas de ensino têm até 2010 para cumprir essa determinação.
} 
que receberiam as crianças. Vale ressaltar que neste ano de 2008 tivemos duas entradas de crianças: as de sete anos, que foram para a primeira série do ensino fundamental de 8 anos, e as de seis anos que foram para o ano 1 do ciclo I do ensino fundamental de 9 anos.

Essa política educacional de implantação do ensino fundamental de 9 anos permitiu uma reorganização no atendimento e um repensar do 'fazer' na educação infantil. As crianças de três anos que, até então, eram atendidas em período integral passaram a ser recebidas nas unidades com período parcial, o que possibilitou uma ampliação do atendimento das crianças de zero a cinco anos.

A segunda foi a dimensão pedagógica com o objetivo de construir uma proposta para o desenvolvimento do trabalho com as crianças de 6 anos no ensino fundamental. Por proposta da equipe pedagógica essa tarefa foi socializada com o coletivo dos profissionais que trabalham na rede municipal e, para tanto, foi constituído um grupo de trabalho. Para compor esse grupo foram convidados profissionais da educação municipal ${ }^{4}$ interessados em debater e elaborar propostas sobre o tema. A coordenação ficou a cargo da equipe pedagógica da secretaria, mais especificamente Alvina, Celisa e Leo que, após a primeira reunião com o grupo, propôs a ampliação da coordenação com a inclusão de professores e educadoras que se dispusessem a ajudar na organização dos encontros. Esse grupo de trabalho se reunia uma vez a cada quinze dias, durante duas horas, em duas turmas, uma pela manhã e outra pela tarde, para possibilitar a participação dos profissionais dos dois períodos de funcionamento das escolas.

Para atingir seu objetivo esse grupo de trabalho partiu de uma discussão sobre infância e o significado da inserção da criança de 6 anos no ensino fundamental. Como referência para questão da infância e suas concepções utilizou-se, dentre outros, Áries (2006) e Walter Benjamin (1994) e para a análise do trabalho pedagógico com crianças a coletânea de textos organizada por representantes do Ministério da Educação (2006).

A principal preocupação da equipe pedagógica da secretaria foi, naquele momento, que essa proposta criasse algo ‘novo' para receber as crianças de 6 anos no ensino fundamental, que não fosse nem o último ano da educação infantil e nem o primeiro do fundamental para as crianças de sete anos. Ao mesmo tempo essa proposta precisava 'nascer'

\footnotetext{
${ }^{4}$ - Nesse primeiro momento de elaboração da proposta os profissionais da educação eram representados por gestoras educacionais, professoras de $1^{\mathrm{a}}$. a $4^{\mathrm{a}}$. séries e educadoras de crianças de 0 a 3 anos (profissionais com formação em níveis fundamental e médio).
} 
no meio dos profissionais que trabalham diretamente com a criança para que estes pudessem se apropriar da proposta.

Com base nos referenciais teóricos utilizados e os debates feitos nos grupos de trabalho foram escolhidos como pilares do currículo o "brincar” e a "expressão artística”. A escolha desses pilares se justifica a partir do princípio de garantia do direito à infância e do respeito à maneira pela qual a criança conhece e concebe o ‘estar no mundo’ .

Ao final do segundo semestre de 2007 a proposta pedagógica sistematizada pelo grupo organizou o conhecimento a ser trabalhado, a partir dos pilares descritos anteriormente, no ano de ingresso das crianças de 6 anos no ensino fundamental em quatro áreas: linguagens, ciências sociais, ciências naturais e noções lógico-matemáticas. Para cada área foram estabelecidas metas, conforme seguem:

\begin{tabular}{|c|c|}
\hline ÁREAS & METAS \\
\hline linguagens & $\begin{array}{l}\text { - identificar todas as letras do alfabeto e sílabas; } \\
\text { - } \text { produzir texto oral, com o professor e/ou a criança como } \\
\text { escriba; } \\
\text { - estimular e proporcionar o contato com diversos portadores } \\
\text { e tipos de texto; } \\
\text { - conhecer e identificar os tipos de textos e portadores } \\
\text { apresentados; } \\
\text { - desenvolver a linguagem oral com coerência e seqüência } \\
\text { lógico-temporal. }\end{array}$ \\
\hline Ciências sociais & $\begin{array}{l}\text { - } \quad \text { perceber que faz parte de uma sociedade e é responsável } \\
\text { por ela; } \\
\text { - } \quad \text { perceber as conseqüências das próprias ações; } \\
\text { - compartilhar vivências; } \\
\text { - conhecer modos de ser, viver e trabalhar de alguns grupos } \\
\text { - } \text { sociais do presente e do passado; } \\
\text { identificar alguns papéis sociais existentes em seus grupos } \\
\text { de convívio, dentro e fora da instituição; } \\
\text { - valorizar o patrimônio cultural do seu grupo social e } \\
\text { interesse por conhecer diferentes formas de expressão } \\
\text { cultural. }\end{array}$ \\
\hline
\end{tabular}




\begin{tabular}{|c|c|}
\hline Ciências naturais & $\begin{array}{l}\text { - } \quad \text { conscientizar-se do próprio corpo; } \\
\text { - } \text { desenvolver a percepção da sensibilidade (auditiva visual e } \\
\text { - } \quad \text { observar a paisagem local (rios, vegetação, construções, } \\
\text { florestas, campos etc.); } \\
\text { - } \quad \text { registrar a observação de mudanças ocorridas nas paisagens } \\
\text { ao longo do tempo; } \\
\text { - } \quad \text { valorizar de atitudes de manutenção e preservação dos } \\
\text { - } \quad \text { identificar matéria prima de produtos que as crianças usam } \\
\text { - } \quad \text { diferenciar recursos naturais (água, solo, ar e calor); } \\
\text { - } \quad \text { conhecer o ecossistema (horta, plantas, bichos); } \\
\text { - } \text { perceber objetos e processos de transformação (fenômenos } \\
\text { - da natureza); } \\
\text { - } \text { diferenciar seres vivos e não vivos; } \\
\text { - conhecer insetos animais domésticos, predador e presa; } \\
\text { conscientizar-se da relação homem e natureza. }\end{array}$ \\
\hline $\begin{array}{l}\text { Noções lógico- } \\
\text { matemáticas }\end{array}$ & $\begin{array}{l}\text { - } \text { desenvolver noções de estimativa, conservação de massa e } \\
\text { volume; } \\
\text { - } \text { resolver problemas diversos com entendimento; (oral } \\
\text { registro através de desenhos matemáticos); } \\
\text { - comparar, classificar, ordenar, agrupar objetos, relacionar o } \\
\text { número à quantidade; } \\
\text { - conhecer a linguagem matemática (formas geométricas } \\
\text { mais comuns, números e símbolos); } \\
\text { - desenvolver as noções dos conceitos das operações } \\
\text { matemáticas (adição, subtração, multiplicação e divisão) } \\
\text { sem técnica operatória; } \\
\text { - desenvolver noções espacial e temporal; } \\
\text { criar consciência corporal (movimento, corpo-corpo, corpo } \\
\text { ambiente). }\end{array}$ \\
\hline
\end{tabular}

A partir de referenciais teóricos como BRANDÃO (1983), FRANCO (1994), GENTILI e SILVA (1994), LUCKESI (1992, 1998, 2000), MACHADO (2003), SOUSA (1997), VASCONCELLOS (1998), VIANNA (1997), dentre outros, o grupo debateu e sistematizou uma proposta de avaliação da aprendizagem. Para tanto, a equipe pedagógica conduziu a discussão em torno de vários aspectos da cultura avaliativa que temos e a que queremos nas nossas escolas.

O ponto de partida foi o reconhecimento, por um lado, da existência de uma cultura escolar que valoriza a avaliação produtora de resultados quantitativos em detrimento de uma avaliação que possibilite a produção de resultados qualitativos. Essa cultura produz e 
justifica práticas avaliativas desenvolvidas nas escolas públicas fundamentadas na lógica “classificatória e excludente” (VASCONCELLOS, 1998, p.39) que proporciona muito mais “o papel de disciplinador” (LUCKESI, 1998, p.37) do que educativo aos professores. Por outro lado o grupo reconheceu a importância da avaliação como instrumento de organização e “bússola” do trabalho pedagógico, desde que bem conduzida.

O que fazer? Questionou a equipe pedagógica ao grupo de trabalho.

Concluímos por priorizar a avaliação qualitativa em detrimento da avaliação quantitativa. Não que isso significasse deixar de atribuir nota ou menção aos alunos, pois enquanto tivermos promoção/retenção devemos ter notas, mas sim que adotaríamos a compreensão coletiva de que os aspectos qualitativos são preponderantes em relação aos quantitativos. Para tanto, deveríamos criar e propor atividades que pudessem gerar arquivos permanentes de observação e registro.

O debate em torno da avaliação suscitou o questionamento sobre a organização burocrática da escola como a periodicidade bimestral de atribuição de notas aos alunos e o conceito atribuído. O grupo de trabalho sugeriu uma revisão nesses procedimentos e propôs a periodicidade de atribuição de notas por semestre e a utilização de apenas três conceitos: AS avanço significativo, AP - avanço parcial e AM - avanço mínimo.

Partindo dessa discussão e da perspectiva de uma avaliação que priorizasse análises qualitativas, o grupo optou pela adoção de “portfólio” (BEAUCHAMP, 2007, p. 97 108) como principal instrumento avaliativo no desenvolvimento do trabalho pedagógico com as crianças de 6 anos.

No livro "Ensino fundamental de 9 anos - orientações para a inclusão da criança de seis anos de idade” (LEAL, ALBUQUERQUE, MORAIS, 2007) do MEC encontramos a definição de portfólio “como um conjunto de documentos - anotações pessoais, experiências de aula, trabalhos pontuais, controles de aprendizagem, conexões com outros temas fora da escola, representações visuais, etc, que ajudam os professores e os familiares a acompanhar o processo de desenvolvimento das crianças” (p. 103).

Além de o portfólio ter como função o registro de como a criança apresenta a sua construção do conhecimento em determinada fase da vida, ele também pode ser um elo significativo entre uma professora e outra(s) e a criança e sua família. 
O portfólio também possibilita que a própria criança observe como está construindo seu conhecimento e acompanhe seus avanços por meio do acesso aos registros das atividades praticadas por ela.

\begin{abstract}
“A avaliação nesta etapa deve ser processual e destinada a auxiliar o processo de aprendizagem, fortalecendo a auto-estima das crianças. No que se refere às crianças, a avaliação deve permitir que elas acompanhem suas conquistas, suas dificuldades e suas possibilidades ao longo de seu processo de aprendizagem." (SANTARÉM; CRUZ, 2008, p.02)
\end{abstract}

O debate no grupo de trabalho foi perpassado também por questões como a periodicidade de atividades avaliativas, a seleção das atividades que significativamente apontam para as construções que as crianças fizeram no período que nos propusemos a analisar e ainda se essas seleções nos permitem utilizar a avaliação como um caminho de mão dupla onde tanto o trabalho do professor quanto os processos construídos pelas crianças são objetos de análise. A sugestão do grupo foi a de socializar esse debate nos HTPC's ${ }^{5}$ das escolas para, coletivamente, cada unidade construir respostas para essas indagações.

Após esse primeiro momento de elaboração da proposta pedagógica para as crianças de 6 anos, a equipe pedagógica assumiu outro desafio - o desdobramento da implantação da proposta pedagógica para o ensino fundamental de 9 anos, com a retomada e sistematização do currículo da rede municipal de Várzea Paulista.

O início dessa sistematização foi no grupo das gestoras educacionais ${ }^{6}$. Paralelamente às reuniões de elaboração da proposta pedagógica para as crianças de 6 anos, a equipe pedagógica da secretaria realizava quinzenalmente reuniões com as gestoras educacionais para discussões teóricas sobre temas pedagógicos e também para a análise e debate de questões do cotidiano escolar.

O trabalho de formação com toda a equipe das gestoras foi intenso. Retomamos o debate em torno da função e o objetivo primeiro da educação que é a criança e a necessidade de organizarmos nosso trabalho tendo a criança como referencial.

\footnotetext{
5 - HTPC é hora do trabalho pedagógico coletivo. Cada professora da rede municipal dispõe de 5 horas semanais remuneradas para essa atividade. As professoras que estão trabalhando com as crianças de 6 anos no ensino fundamental, além dessas 5 horas, dispõem de mais 2 horas.

${ }^{6}$ - Esse grupo é formado pelas diretoras, vice - diretoras e coordenadoras pedagógicas da rede municipal. É composto por, aproximadamente, 50 profissionais.
} 


\title{
RELATO DE EXPERIÊNCIA
}

\section{Área Temática: Educação Visual, Linguagens Visuais e Arte}

Nesse grupo foram discutidos dois temas de fundamental importância para fortalecimento da proposta curricular para a rede municipal: ‘sistema’ e ‘identidade’.

Para a compreensão de sistema utilizamos o conceito de Saviani (2005), no qual, sistema é “a unidade de vários elementos intencionalmente reunidos, de modo a formar um conjunto coerente e operante” (p. 80, grifos do autor).

Para identidade utilizamos o conceito que Tomaz Tadeu sintetiza como:

\begin{abstract}
“A identidade cultural ou social é o conjunto daquelas características pelas quais os grupos sociais se definem como grupos: aquilo que eles são. Aquilo que eles são, entretanto, é inseparável daquilo que eles não são, daquelas características que os fazem diferentes de outros grupos. Identidade e diferença são, pois, processos inseparáveis. A identidade cultural não é uma entidade absoluta, uma essência, uma coisa da natureza, que faça sentido em si mesma, isoladamente. Na vida cotidiana, na experiência 'normal' da existência, essa estreita dependência entre identidade e diferença desaparece, se apaga, se torna invisível. Tanto a nossa identidade quanto a identidade dos outros (a diferença) aparecem como absolutas, como essências, como experiências originais, primordiais. A identidade só faz sentido numa cadeia discursiva de diferenças: aquilo que 'é' é inteiramente dependente daquilo que 'não é'.” (SILVA, 1999, p. 46)
\end{abstract}

A partir das discussões nesse grupo adotamos como referência para a identidade do sistema municipal os princípios: “a criança é sujeito do processo educativo” e "a criança é resultado do processo histórico e produtora da história”.

Essas referências produziram os eixos para a elaboração e o desenvolvimento do trabalho pedagógico e educativo no município, são eles:

- a criança constrói o seu ‘eu’ na sua relação com o ‘outro’;

- 'brincar' é constitutivo da criança e deve ser método de conhecimento e garantia do direito à infância;

- a construção da identidade dos sujeitos deve passar pelo reconhecimento e respeito às diferenças e recusa a toda e qualquer forma de intolerância, preconceito e/ou discriminação;

- garantia à inclusão social, no seu sentido mais amplo, inclusive no conhecimento.

Nesse momento da sistematização a equipe gestora julgou necessária a socialização de todas as produções obtidas nos diferentes grupos e a constituição de um único grupo para dar continuidade à reelaboração e sistematização da proposta curricular para a rede municipal de Várzea Paulista. Assim, foi formado um grupo com as professoras que estavam 
trabalhando com as turmas de 6 anos no fundamental, que dispunham de 2 horas remuneradas semanais para essa participação, e os demais profissionais da rede que quisessem participar.

Esse grupo elaborou, com base nas discussões acumuladas anteriormente e a legislação vigente, os objetivos do sistema de educação municipal de Várzea Paulista.

A questão que nos colocávamos era: como queremos que as crianças saiam da rede municipal?

Após várias discussões foram selecionados os objetivos: identidade, autonomia, domínio das diferentes linguagens e raciocínio lógico, cooperação, solidariedade e convívio social, criticidade, "vontade de crescer”, esperançar, responsabilidade e compromisso, como nossas referências e detalhamos a compreensão do grupo do significado desses objetivos. As respostas construídas ficaram assim sistematizadas e definidas:

Identidade: Conhecer a si mesmo, o que quer para si e em que meio quer viver; Conhecer a comunidade, a família, reconhecer-se e apropriar-se das semelhanças e diferenças; Perceber que as culturas são diferentes entre si e que todas devem ser respeitadas.

Autonomia: Agir com coerência e consciência; Dominar os diferentes tipos de comunicação; Conscientizar-se que a ação é reflexiva e que tem o outro como referência; Conhecer e seguir as regras de acordo com o local e as pessoas que fazem parte do convívio.

Domínio das diferentes linguagens e Raciocínio Lógico: Organizar e exercitar o pensamento, estabelecendo relações com o conhecimento e direcionar a ação no sentido de solucionar questões, para tornar a vida melhor; Ser curioso para novos conhecimentos; Problematizar fatos.

Cooperação, Solidariedade e Convívio Social: Compartilhar experiências; Tornar-se agente na criação de um ambiente acolhedor; Perceber a necessidade do outro e colocar-se à disposição para ajudar; Saber respeitar as diferenças e a individualidade; Ampliar as possibilidades de comunicação.

Criticidade: Posicionar-se e expressar-se claramente através de argumentos, aprender a ser e aprender a fazer;

“Vontade de crescer”, Esperançar: Ter vontade de crescer e sonhar. 
Responsabilidade e Compromisso: Participar da conservação e melhoria cultural, social, ecológica; Cumprir seus deveres por iniciativa própria; Conscientizar-se das conseqüências de suas próprias ações.

Esses objetivos devem ser referências no desenvolvimento do trabalho de cada uma das escolas e, conseqüentemente, de todos os professores da rede municipal. Os conteúdos devem ser trabalhados de forma que esses objetivos sejam vislumbrados como finalidade da educação no município.

Como gestoras do sistema da rede municipal, analisando o caminho percorrido até aqui, reconhecemos (e comemoramos!) muitos avanços. Ao mesmo tempo constantemente nos surpreendemos com as necessidades que ainda estão por vir e os desafios ainda em construção, como por exemplo, o currículo que deverá ser trabalhado por todos os profissionais da rede municipal em todos os anos no ensino fundamental de 9 anos, como também na educação infantil. Essa é a tarefa que se apresenta no momento!

Mesmo que provisoriamente, a seguir teceremos algumas análises sobre as conseqüências e as resistências da implantação dessa política. Algumas dessas análises são empíricas e outras operacionais. Vale ressaltar que todas essas análises foram objeto de longas discussões da equipe pedagógica nas nossas reuniões de estudo e planejamento. É nesses espaços que buscamos sustentação umas nas outras para que o foco do trabalho não se perca para podermos continuar o diálogo produtivo com a rede.

\section{O MEIO DO CAMINHO}

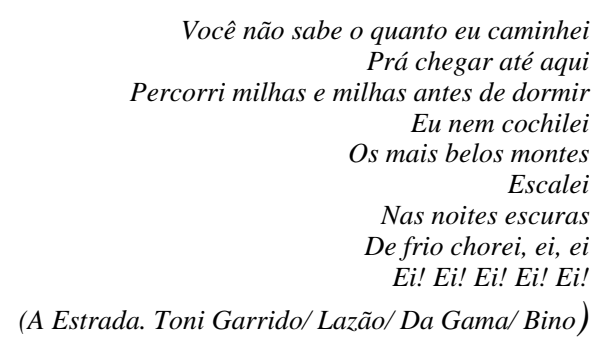

É nesse momento que nos encontramos agora. Na estrada...

Toda a discussão feita na rede municipal até agora resvalou em vários aspectos do funcionamento das escolas e provocou questionamento sobre seus mais diversos aspectos. Um desses aspectos é a organização e o funcionamento do trabalho coletivo nas escolas. Por 
sugestão do grupo de professores ainda precisamos discutir e elaborar melhor como deve ser dar o trabalho pedagógico coletivo para atingir os objetivos que decidimos para nossos alunos. Duas questões estão muito claras para todos: não pode ser do mesmo jeito que vem sendo feito e o ‘novo jeito’ deve ser construído coletivamente.

Outro aspecto que está em ebulição é a organização dos conselhos de classe e série e as reuniões de pais. Essa organização atendia aos interesses de uma escola que utilizava a avaliação como instrumento de atribuições de notas com o objetivo de aprovar e reprovar alunos. Se estamos mudando isso, qual o sentido que tem esse conselho? O grupo respondeu que nenhum. Outra pergunta surgiu: o que colocar no lugar? O que fazer com isso? Como? Enfim... Questionamento parecido teve o objetivo e a periodicidade das reuniões de pais. Se não teremos mais notas bimestrais chamaremos os pais nas escolas para quê? Se não será em bimestres quando será?

Nosso foco será voltado para construir, coletivamente, respostas para todas essas indagações.

Como é muito recente a inclusão das crianças de 6 anos ensino fundamental, algumas professoras e gestoras têm trazido para o grupo relatos de pais que não levam 'a sério’ essa etapa na vida dos seus filhos, julgando que ‘quando chove não precisa ir...’ É como se a obrigatoriedade de ter uma freqüência mínima de 75\% valesse somente para crianças com 7 anos. Sentimos que, para o próximo ano, precisamos criar alternativas para esclarecermos mais a população do significado do ensino fundamental de 9 anos. Para isso, estamos discutindo e elaborando propostas com as gestoras das unidades de ensino fundamental.

O principal foco de resistência está nos próprios profissionais da rede municipal que estão sentindo a onda da mudança e não querem nem participar do processo de discussão e elaboração das propostas, justificando que não vão mudar porque 'sempre foi assim...' Estamos discutindo e trabalhando diretamente com essas pessoas, pois, brevemente, todas terão que assumir as propostas que estão sendo elaboradas hoje, como a adoção dos portfólios, por exemplo.

É importante ressaltar outra percepção que tivemos de foco de resistência, essa na educação infantil. Como dissemos a implantação do ensino fundamental de 9 anos permitiu a ampliação e reorganização no atendimento da educação infantil, fazendo com que crianças de três anos, que até então eram atendidas por unidades em período integral fossem para aquelas 
com período parcial. As professoras dessas unidades ficaram, inicialmente, muito apreensivas e temerosas com o desenvolvimento de seu trabalho para essa faixa etária.

Uma dificuldade que encontramos, e que sustenta algumas resistências existentes na rede, é o fato de termos que conviver com o ensino fundamental de 8 anos até 2011. Para podermos implantar o ensino fundamental de 9 anos em 2008 tivemos que atender as crianças de 7 anos no ensino fundamental de 8 anos. Estas sairão do sistema em 2011 e, somente depois desse ano, o ensino fundamental de 8 anos (e toda a sua organização) será extinto no sistema municipal.

Como a participação e o coletivo nem sempre fizeram parte do cotidiano dos profissionais da educação municipal de Várzea Paulista, pois há bem pouco tempo o controle do que se falava e se fazia era uma prática bem mais comum, podemos afirmar que não estamos somente construindo o ‘novo’ para as crianças que passarão a freqüentar as escolas da cidade. Essas iniciativas promovem também a possibilidade de emancipação dos próprios professores, coordenadores e diretores da rede, na medida em que os coloca como protagonistas de tudo o que estamos propondo. Pois como diz Rancière (2005) “para emancipar a outrem, é preciso que se tenha emancipado a si próprio. É preciso conhecer-se a si mesmo como viajante do espírito, semelhante a todos os outros viajantes, como sujeito intelectual que participa da potência comum dos seres intelectuais” (p. 57).

É importante relatarmos que esse ‘novo’ não está sendo construído a partir do consenso e da harmonia. A participação dos professores não foi algo que conseguimos com tranqüilidade. Nossos encontros são sempre perpassados por enfrentamentos, ironias, contradições, insatisfações, muitas dúvidas e discordâncias... Nem por isso deixamos de valorizar nossa metodologia de construção e acreditar nela. E acreditamos, principalmente, que as construções de conhecimentos sempre se dão a partir de um ponto de desestabilização para depois sr estabilizar novamente com novas possibilidades e novas organizações.

Por tudo isso, temos a certeza, assim como Thiago de Mello, que não temos caminho novo. O que temos de novo é o jeito de caminhar. 


\section{REFERÊNCIAS}

ARIÈS, P. História social da criança e da família. 2. ed. Rio de Janeiro, Rio de Janeiro: LTC, 2006.

BEAUCHAMP, J. Ensino fundamental de nove anos: orientações para a inclusão de seis anos de idade. Brasília, Ministério da Educação: FNDE, Estação Gráfica, 2007.

BENJAMIN, W. Reflexões sobre a criança, o brinquedo e a educação. $1^{\mathrm{a}}$ ed. São Paulo : Duas Cidades, Editora 34, 2002.

BRANDÃO, Z., BAETA, A., ROCHA, A. Evasão e repetência no Brasil: a escola em questão. Rio de Janeiro: Achiamé, 1983.

FRANCO, M. Qualidade de ensino: velho tema, novo enfoque. INEP/MEC, Série Documental: Relatos de Pesquisa, Brasília, n. 17, maio de 1994.

GENTILI, P.; SILVA, T. (Orgs.). Neoliberalismo, qualidade total e educação. Petrópolis, Rio de Janeiro: Vozes, 1994.

LEAL, T., ALBUQUERQUE, E. e MORAIS, A. Avaliação e aprendizagem na escola: a prática pedagógica como eixo da reflexão. In: BEAUCHAMP, J. Ensino fundamental de nove anos: orientações para a inclusão de seis anos de idade. Brasília, Ministério da Educação: FNDE, Estação Gráfica, 2007.

LUCKESI, C. Planejamento e avaliação na escola: articulação e necessária determinação ideológica. Idéias 15, São Paulo: FDE, 1992.

Avaliação da aprendizagem escolar. $7^{\circ}$ edição, São Paulo: Cortez,1998.

Alegre, 2000.

O que é mesmo o ato de avaliar a aprendizagem? Revista Pátio 12, Porto

MACHADO, C. Avaliar as escolas estaduais para quê - uma análise do uso dos resultados do SARESP 2000. 2003. Tese de (Doutorado) - Faculdade de Educação da Universidade de São Paulo, 2003.

RANCIÈRE, J. O mestre ignorante - cinco lições sobre a emancipação intelectual. $2^{\mathrm{a}}$ ed. Belo Horizonte, Autêntica, 2005.

SANTARÉM, M., CRUZ, M. Avaliação formativa na educação infantil. Pedago Brasil, Pedagogia e psicopedagogia. Disponível em:

< http://www.pedagobrasil.com.br/pedagogia/avaliaçãoformativa.htm>. Acesso em 2008.

SAVIANI, D. Educação brasileira. Estrutura e sistema. 9. ed. Campinas: Autores Associados, 2005.

SILVA, T. O currículo como fetiche: a política e a poética do texto curricular. Belo Horizonte: Autêntica, 1999. 
SOUSA, C. (Org.). Avaliação do rendimento escolar. 6 edição. Campinas: Papirus, 1997.

VASCONCELLOS, C. Avaliação da aprendizagem: práticas de mudança. São Paulo: Libertad, 1998.

VIANNA, H. Avaliação: considerações teóricas e posicionamentos. In: Estudos em Avaliação Educacional, São Paulo: Fundação Carlos Chagas, n. 16, jul./dez. 1997. 
Professora, Diretora pedagógica da Educação Infantil de 0 a 3 anos da Secretaria Municipal de Educação, Cultura, Esporte e Lazer da Prefeitura Municipal de Várzea Paulista, localizada na Rua José Dias de Castro 410 fones(11) 45951160/45951161/45951162, fones(11) 45954343/ (11) 83583436 E-mail: alvasouza04@hotmail.com

CELISA CARRARA BONAMIGO

Professora, Supervisora de Ensino da Secretaria Municipal de Educação,

Cultura, Esporte e Lazer da Prefeitura Municipal de Várzea Paulista, localizada à Rua José Dias de Castro 410 - fones (11) 45951160/45951161/45951162, , fones (11) 45871066/ (11) 97446531 E-mail: celisa bonamigo@yahoo.com

CRISTIANE MACHADO

Professora, Supervisora Departamental Pedagógica da Secretaria Municipal de Educação, Cultura, Esporte e Lazer da Prefeitura Municipal de Várzea Paulista, localizada na Rua José Dias de Castro 410 - fones (11) 45951160/45951161/45951162, , fones (19) 96052138/ (11) 71502245 E-mail: cristiane13machado@yahoo.com.br

LEONICE DE BRITO

Professora, Diretora Pedagógica da Educação Infantil de 3 a 5 anos da Secretaria Municipal de Educação, Cultura, Esporte e Lazer da Prefeitura Municipal de Várzea Paulista, localizada na Rua Jósé Dias de Castro 410 fones ( 11 ) 45951160/ 45951161/ 45951162, fones ( 11 ) 72210975/ 4595408

E-mail: brito211@itelefonica.com.br 